\title{
Larvas de quarto e quinto estádios e pupa de Dasyophthalma creusa creusa (Hübner) (Lepidoptera, Nymphalidae, Brassolinae) ${ }^{1}$
}

\author{
Mirna M. Casagrande ${ }^{2} \&$ Olaf H.H. Mielke ${ }^{2}$
}

1 Contribuição número 1183 do Departamento de Zoologia, Universidade Federal do Paraná.

${ }^{2}$ Departamento de Zoologia, Universidade Federal do Paraná. Caixa Postal 19020, 81531-980 Curitiba, Paraná, Brasil. Bolsista do CNPq.

\begin{abstract}
Fourth and fifth larval instars and pupa of Dasyophthalma creusa creusa (Hübner). (Lepidoptera, Nymphalidae, Brassolinae). Descriptions of the fourth and fifth larval instars and pupa of Dasyophthalma creusa creusa (Hübner [1821]) from material reared in southern Brasil are presented and illustrated. The larva feed on leaves of Geonoma schottiana Martius (Arecaceae).
\end{abstract}

KEY WORDS. Hostplant, immature stages.

As espécies do gênero Dasyophthalma Westwood, 1851, quando comparadas com as espécies de outros gêneros da subfamília são classificadas como de médio porte, isto é, não tão grandes como as de Caligo Hübner, [1819] e nem tão pequenas como as de Narope Doubleday, [1849]. São habitantes das florestas subtropicais nas costas leste e sul do Brasil. O vôo é lento quando nas partes mais densas da mata e mais rápido nas trilhas abertas e nos horários de sol intenso, diferente portanto da grande maioria das espécies de outros gêneros de Brassolinae que possuem hábitos crepusculares.

Neste trabalho descrevem-se e ilustram-se as larvas de quarto e quinto estádios, pupa e, ilustra-se o adulto de Dasyophthalma creusa creusa provenientes de Rio Natal, São Bento do Sul, Santa Catarina, Brasil, 500 m. A nomenclatura das áreas do corpo da larva estão descritas conforme definidas em Peterson (1962) e da pupa como em Casagrande (1979).

\section{Larva de quarto estádio (Fig. 1)}

Cabeça: de textura irregular e forma quadrangular, porém não comprimida dorso-ventralmente como em $D$. rusina rusina (Godart, [1824]). Coloração geral verde, com pequenos pontos pretos nas depressões das irregularidades. Na região posterior, três pares de escolos: dorsais, látero-dorsais e látero-ventrais, em castanho avermelhado com pontos amarelados, direcionados para o tórax e não para cima como nas espécies de Caligo e aumentando de tamanho em direção ao vértice. Do anel de estemas em direção aos escolos, duas linhas de pontos mais escuros, uma do anel até a base do escolo dorsal e outra até o látero-dorsal, esta dividida em duas linhas; uma escura e superior e outra clara e inferior. Partindo da área do anel de estemas e com a mesma coloração escura das linhas que atingem os escolos dorsal e látero-dorsal, tufo de cerdas projetadas anteriormente. Sutura epicranial acentuadamente marcada por pontos mais escuros. Cerdas claras, distribuídas por todas as áreas inclusive nos escolos (Fig. 1)

Tórax e abdome pubescentes de coloração geral verde com faixas longitudinais em diferentes tons de verde e amarelo cítrico. As cerdas são simples, claras como as da cabeça, sobre pináculos branco leitoso. Faixa mediana dorsal do mesotórax até o último segmento abdominal, entre as projeções da placa suranal, em amarelo intenso e cítrico; é mais estreita nos segmentos torácicos e atinge a largura máxima no terceiro e quarto segmentos abdominais, estreitando novamente até o último segmento. Esta faixa amarela é interrompida entre os segmentos abdominais três e quatro, parte posterior dos segmentos cinco, seis e sete, por mancha preta com branco no centro; a primeira maior e as três posteriores decrescem de tamanho. Faixa longitudinal lateral verde pouco mais claro que o tegumento e contornada, tanto superior como inferiormente, por linha estreita amarelo cítrico. Faixa espiracular verde mais intensa e peritrema dos espiráculos castanho escuro. Projeções da placa suranal da mesma cor do tegumento, pináculos cônicos, maiores que do tórax e abdome (Fig. 1).

Neste estádio a camuflagem com o substrato é acentuada. Escolos e manchas escuras ao longo da faixa mediana dorsal lembram as manchas de fungo nas folhas (Fig. 1).

\section{Larva de quinto estádio (Figs 2 e 3)}

Cabeça: como no estádio anterior, porém com os escolos em vermelho carmim e de extremidade mais arredondada. Mancha arredondada, branca, mediana entre a base da mandíbula e a base do escolo dorsal.

Tórax e abdome pubescentes, de coloração geral verde, com faixas e estrias longitudinais em diferentes tons de verde, 

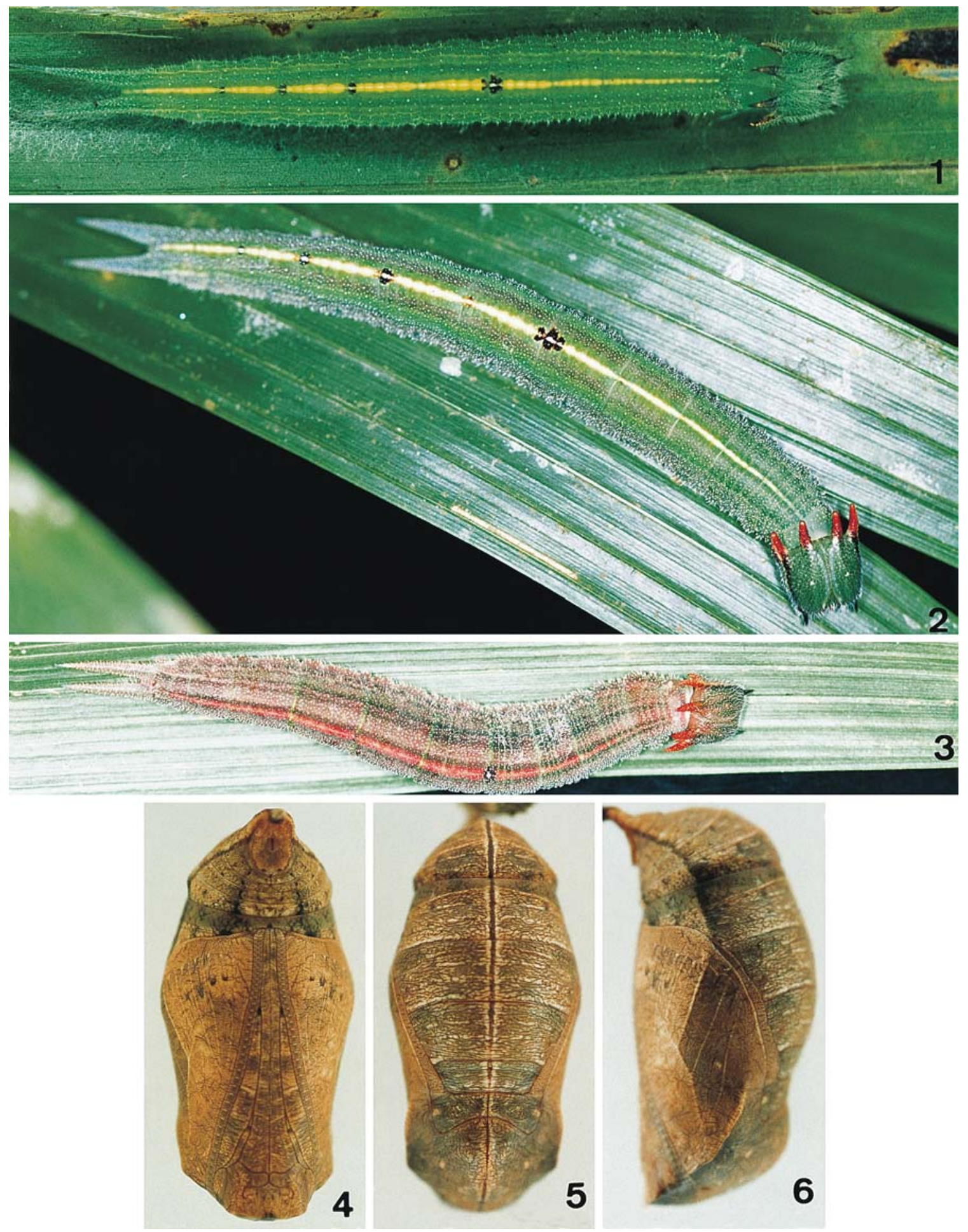

Figuras 1-6. Dasyophthalma creusa creusa: (1) larva de quarto estádio, vista dorsal; (2-3) larvas de quinto estádio, vista dorsal; (4-6) pupa, vista ventral, dorsal e lateral respectivamente.

Revista Brasileira de Zoologia 20 (1): 157-160, março 2003 

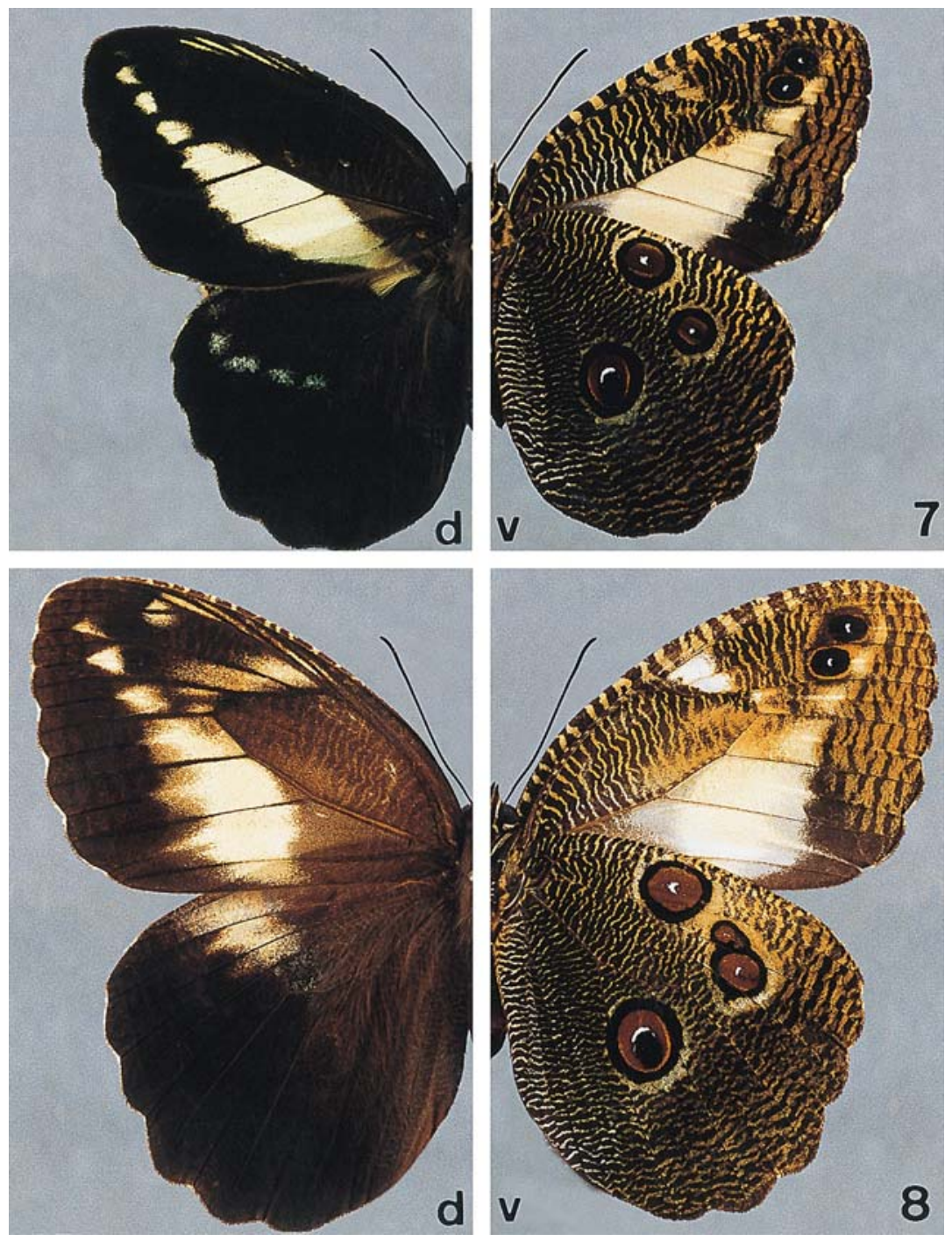

Figuras 7-8. Dasyophthalma creusa creusa, macho: (7) vistas dorsal (d) e ventral (v), (8) fêmea: vistas dorsal e ventral.

verde com cinza e amarelas. Faixa mediana dorsal com a mesma distribuição de manchas pretas, pouco maiores sobre amarelo não tão intenso como no estádio anterior. Faixa subdorsal, verde musgo com pontuações em cinza escuro desde o tórax até a base das projeções caudais. Faixa espiracular com a mesma coloração da anterior, porém mais larga. Peritrema dos espiráculos, como no estádio anterior.

As larvas passam por uma alteração drástica de coloração quando próximas de pupas. Adquirem a cor vermelho carmim, semelhante a dos escolos, alternando faixas longitudinais nesta cor e em verde musgo, e assim permanecem por aproximadamente dois dias (Fig. 3).

Planta hospedeira: alimentam-se de folhas de Geonoma schottiana Martius (Arecaceae), normalmente no início da manhã e no final da tarde e repousam isoladamente sob as folhas, na nervura central, próximas à base das mesmas durante grande parte do dia.

Atingem um comprimento máximo de $9 \mathrm{~cm}$, incluindo as projeções da placa suranal.

\section{Pupa (Figs 4-6)}

Coloração geral parda com mesclas escuras e claras. Teca alar de contorno uniforme desde a base até a porção distal, sem manchas de aspecto espelhado e não projetadas como em D. rusina rusina

Ventralmente, cabeça e tórax mais claros, com manchas escurecidas de tamanhos distintos e disformes. Antenas, pernas e asas com contorno em castanho. Próximo à margem das asas, 
duas linhas de pequenas manchas arredondadas, formando um semiciculo, a linha anterior mais escura e a distal, imediatamente a esta, mais clara. Linha mediana dorsal marcada por faixa castanho-escura. Abdome, tanto dorsal como ventralmente, pardo mais intenso que a cabeça e o tórax, sem linhas oblíquas de cor escura como citadas por Casagrande \& MielKe (2000b) para D. rusina rusina, Young \& MuYshondt (1985) para Caligo atreus (Kollar, 1850) e Caligo memnon (C. Felder \& R. Felder, 1867), e para Caligo martia (Godart, [1824]) por CASAGRANDE \& MielKe (2000a). O maior comprimento das pupas variou entre 3 e $3,2 \mathrm{~cm}$ e a maior largura entre 1,6 e 1,8 cm.

Este período tem uma duração média de 20 dias, com as larvas de quinto estádio formando a pupa em meados de dezembro e os adultos (Figs 7 e 8) emergindo em janeiro, sendo a espécie univoltina.

\section{AGRADECIMENTO}

Ao Prof. Dr. Armando Cervi do Departamento de Botânica da Universidade Federal do Paraná pela identificação da planta hospedeira.

\section{REFERÊNCIAS BIBLIOGRÁFICAS}

Bönninghausen, V. von. 1896. Beitrag zur Kenntnis der Lepidop-
teren-Fauna von Rio de Janeiro. Verhandlungen des Vereins für naturwissenschaftliche Unterhaltung zu Hamburg 9: 19-41.

Casagrande, M.M. 1979. Sobre Caligo beltrao (Illiger). I: Taxonomia, Biologia, Morfologia das Fases Imaturas e Distribuições Espacial e Temporal (Lepidoptera, Satyridae, Brassolinae). Revista Brasileira Biologia, Rio de Janeiro, 39 (1): 173-193.

Casagrande, M.M. \& O.H.H. Mielke. 2000. Larva de quinto estádio e pupa de Caligo martia (Godart) (Lepidoptera, Nymphalidae, Brassolinae). Revista Brasileira de Zoologia, Curitiba, 17 (1): 75-79.

. 2000. Larva de quinto estádio e pupa de Dasyophthalma rusina rusina (Godart) (Lepidoptera, Nymphalidae, Brassolinae). Revista Brasileira de Zoologia, Curitiba, 17 (2): 401-404.

Peterson, A. 1962. Larvae of Insects. An Introduction to Neartic Species. Part. I Lepidoptera and Plant Infesting Hymenoptera. Ann Arbor, Edwards Brothers Inc., 315p.

Yong, A.M. \& A. Muyshondt. 1985. Notes on Caligo memnon Felder and Caligo atreus Kollar. (Lepidoptera: Nymphalidae: Brassolinae) in Costa Rica and El Salvador. The Journal of Research on the Lepidoptera, Beverly Hills, 24 (2): 154175.

Recebido em 01.VIII.2002; aceito em 15.III.2003. 